\title{
Automating the Human Factors Engineering and Evaluation Processes
}

by

C. Mastromonico

Westinghouse Savannah River Company

Savannah River Site

Aiken, South Carolina 29808

R. Izard

A document prepared for IEEE CONFERENCE ON HUMAN FACTORS AND POWER PLANTS at Scottsdale, AZ, USA from 9/15/2002 - 9/19/2002.

\section{DOE Contract No. DE-AC09-96SR18500}

This paper was prepared in connection with work done under the above contract number with the U. S. Department of Energy. By acceptance of this paper, the publisher and/or recipient acknowledges the U. S. Government's right to retain a nonexclusive, royalty-free license in and to any copyright covering this paper, along with the right to reproduce and to authorize others to reproduce all or part of the copyrighted paper. 
This document was prepared in conjunction with work accomplished under Contract No. DE-AC09-96SR18500 with the U. S. Department of Energy.

\section{DISCLAIMER}

This report was prepared as an account of work sponsored by an agency of the United States Government. Neither the United States Government nor any agency thereof, nor any of their employees, makes any warranty, express or implied, or assumes any legal liability or responsibility for the accuracy, completeness, or usefulness of any information, apparatus, product or process disclosed, or represents that its use would not infringe privately owned rights. Reference herein to any specific commercial product, process or service by trade name, trademark, manufacturer, or otherwise does not necessarily constitute or imply its endorsement, recommendation, or favoring by the United States Government or any agency thereof. The views and opinions of authors expressed herein do not necessarily state or reflect those of the United States Government or any agency thereof.

This report has been reproduced directly from the best available copy.

Available for sale to the public, in paper, from: U.S. Department of Commerce, National Technical Information Service, 5285 Port Royal Road, Springfield, VA 22161, phone: (800) 553-6847, fax: (703) 605-6900

email: orders@ ntis.fedworld.gov

online ordering: http://www.ntis.gov/support/index.html

Available electronically at http://www.osti.gov/bridge

Available for a processing fee to U.S. Department of Energy and its contractors, in paper, from: U.S. Department of Energy, Office of Scientific and Technical Information, P.O. Box 62, Oak Ridge, TN 37831-0062,

phone: (865)576-8401,

fax: (865)576-5728

email: $\underline{\text { reports@ adonis.osti.gov }}$ 


\section{Automating the Human Factors Engineering and Evaluation Processes}

(U)

Document No.: PEC-SPS-2002-0015

May 8, 2002

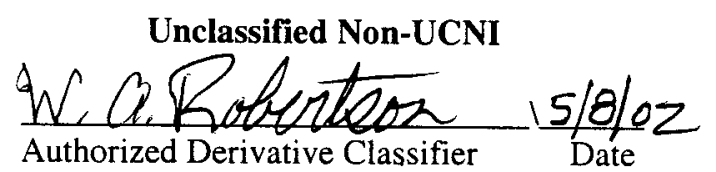

Prepared by: Charles Mastromonico

PE\&CD/P\&CT

and

Richard Izard

$\mathrm{PE} \& \mathrm{CD} / \mathrm{P} \& \mathrm{CT}$ 


\title{
Automating the Human Factors Engineering and Evaluation Processes
}

\author{
Charles R. Mastromonico, and Richard D. Izard are with the Westinghouse Savannah River Company, \\ Aiken, SC 29808
}

\begin{abstract}
The Westinghouse Savannah River Company (WSRC) has developed a software tool for automating the Human Factors Engineering (HFE) design review, analysis, and evaluation processes. The tool provides a consistent, cost effective, graded, user-friendly approach for evaluating process control system Human System Interface (HSI) specifications, designs, and existing implementations. The initial set of HFE design guidelines, used in the tool, was obtained from NUREG0700. Each guideline was analyzed and classified according to its significance (general concept vs. supporting detail), the HSI technology (computer based vs. non-computer based), and the HSI safety function (safety vs. non-safety). Approximately $10 \%$ of the guidelines were determined to be redundant or obsolete and were discarded. The remaining guidelines were arranged in a Microsoft Access relational database, and a Microsoft Visual Basic user interface was provided to facilitate the HFE design review. The tool also provides the capability to add new criteria to accommodate advances in HSI technology and incorporate lessons learned. Summary reports produced by the tool can be easily ported to Microsoft Word and other popular PC office applications. An IBM compatible PC with Microsoft Windows 95 or higher is required to run the application.
\end{abstract}

Index Terms-Human Factors Engineering, Human System Interface, Process Control System, and Design Review.

\section{NOMENCLATURE}

$\begin{array}{ll}\text { DRG } & \text { - Design Review Guide } \\ \text { HFE } & \text { - Human Factors Engineering } \\ \text { HFE-AT } & \text { - Human Factors Engineering Analysis Tool } \\ \text { HSI } & \text { - Human System Interface } \\ \text { NRC } & \text { - Nuclear Regulatory Commission } \\ \text { PC } & \text { - Personal Computer } \\ \text { SRS } & \text { - Savannah River Site } \\ \text { WSRC } & - \text { Westinghouse Savannah River Company }\end{array}$

\section{INTRODUCTION}

$\mathrm{H}$ uman factors have been a major consideration in the design of process control system human system interfaces (HSI) at the Savannah River Site (SRS). A significant effort has been made to minimize the occurrence of human errors in the operation of nuclear materials processing and handling

This work was supported by the U.S. Department of Energy Savannah River Site under contract to Westinghouse Savannah River Company.

Charles. R. Mastromonico is with the Westinghouse Savannah River Company, Aiken, SC 29808 USA (e-mail: charles.mastromonico@srs.gov).

Richard D. Izard is with the Westinghouse Savannah River Company, Aiken, SC 29808 USA (e-mail: rich.izard@ srs.gov). facilities in order to ensure worker safety and avoid costly outages and maintenance. Evaluating a new or existing HSI design can be an arduous process. The level of effort required is typically proportional to the complexity of the process control system, the functional requirements of the HSI, and the degree to which operator actions and capabilities have been analyzed. There are numerous standards available that provide guidance in conducting HFE evaluations. IEEE Std 1023 [1] provides guidance on the integration of HFE into the design, operation, and maintenance of nuclear power plants. IEEE Std 1046 [2] and IEEE Std 1289 [3] provide HFE design guidance for digital control and monitoring systems in nuclear power facilities. IEEE Std 845 [4] presents a discussion of proven HFE techniques and their application to performance issues. NUREG-0700 [5] provides the most comprehensive and detailed guidance for evaluating control system and control room design and has been adopted by the Savannah River Site as its standard of choice.

Like most of these standards, NUREG-0700 was developed for analyzing control systems in nuclear power plants. However, much of the guidance contained in NUREG-0700 can be applied to non-reactor facilities using a graded approach that considers the complexity of the control system HSI and its potential impact on plant safety, the environment, product quality, and the cost of operating and maintaining the plant. Conducting an HFE evaluation of a process control system HSI per NUREG-0700 is no small task. NUREG-0700 contains more than 1600 separate design guidelines for consideration that cover everything from information display to control room layout. A computer application, entitled DRG, for Design Review Guide, was developed for the NRC by Brook Haven National Laboratory in the mid 1990s to assist in the HFE evaluation process. The DRG application provided an interactive means for selecting appropriate guidelines, indicating their relevance to the HSI design in question, and documenting the results of the evaluation process. However, using DRG was quite tedious and often resulted in inconsistencies in applying the guidelines due to different user preferences and interpretations. In addition, DRG produced reports that were not easily exported to today's popular office applications.

The Westinghouse Savannah River Company developed a software tool entitled HFE-AT (Human Factors Engineering Analysis Tool) that addresses the limitations of DRG and provides a consistent, cost effective, user friendly, and graded approach to conducting HFE evaluations. 
PEC-SPS-2002-0015

\section{AUTOMATING THE EVALUATION PROCESS}

NUREG-0700 contains an HFE design review methodology and an established set of guidelines for identifying and correcting HFE deficiencies in control system HSI designs. The objectives of applying this methodology are maximizing human performance and minimizing human error. NUREG0700 is a compilation of relevant guidance extracted from many recognized sources including those referenced in this paper. The design review methodology and guidelines contained in NUREG-0700 can be applied to identify deficiencies in new and existing HSIs or to specify HFE design and performance requirements for future control systems. The methodology uses established practices to capture operator experience, analyze tasks and functions which rely on HSI elements, verify HSI design against functional requirements and human limitations, and validate performance of HSI elements in an integrated system.

NUREG-0700 uses a proven set of more than $1600 \mathrm{HFE}$ guidelines as a basis for conducting design reviews and formulating HSI design requirements. The main design areas in the set include: Information Display, User-System Interaction, Alarm Review, Analysis and Decision Aids, Interpersonnel Communications, Workplace Design, and Local Control Stations.

\section{A. Need to Automate}

After using NUREG-0700 to evaluate several existing process control systems, it became readily apparent that some means of automation was in order to facilitate the lengthy and detailed evaluation process. The process involved selecting the applicable guidelines, evaluating the HSI design against each guideline, tracking the status of the evaluation process, and documenting the final results. Recognizing the need to make the evaluation process more efficient, the NRC provided the DRG software tool. While DRG automated the basic functions of the evaluation process, it was cumbersome to use and the selection process remained tedious. Guideline selection was performed manually. DRG still placed the burden of guideline selection on the evaluator and was subject to inconsistent results due to differences in evaluator preferences and interpretations of individual guidelines. Evaluation status and result reports were cryptic and incompatible with most desktop applications.

\section{B. Taking a Graded Approach}

NUREG-0700 contains 1648 HFE guidelines distributed over the eight design areas listed above. Each design area is further broken down into as many as four sub-levels containing detailed design guidance on specific HSI functions and features that fall under that design area. Individual guidelines are given equal consideration, independent of the level of design detail.

WSRC employed a team of HFE experts to analyze the NUREG-0700 guidelines. From this analysis, it became apparent that the HFE evaluation process could be made more consistent and more efficient by classifying the guidelines and applying a graded approach to guideline selection. Of the
Page 2 of 5

1648 NUREG-0700 guidelines, 181 (almost $11 \%$ ) were immediately eliminated because they either involved obsolete technology or were redundant to other guidelines, and hence, provided no added value. Further analysis of the remaining NUREG-0700 guidelines indicated that approximately $7 \%$ involved general design concepts while $42 \%$ provided detailed guidance to support the more general concepts. The remaining $51 \%$ were unique guidelines that were considered standalone. About $48 \%$ of the guidelines applied only to computer based HSIs, 20\% involved non-computer based HSIs, and $32 \%$ could be applied to both. Approximately 45 $\%$ of the guidelines were determined to be appropriate for the design of safety functions, while $55 \%$ applied to all systems. Table 1 summarizes the results of this categorization process.

TABLE I

CATEGORIZATION OF NUREG-0700 HFE GUIDELINES

\begin{tabular}{|l|l|c|l|}
\hline Category & Classification & $\%$ & Guideline Characteristic \\
\hline \multirow{4}{*}{$\begin{array}{l}\text { Design } \\
\text { Detail }\end{array}$} & $\begin{array}{l}\text { General } \\
\text { Concept }\end{array}$ & $7 \%$ & $\begin{array}{l}\text { Encompasses the scope of } \\
\text { several other guidelines }\end{array}$ \\
\cline { 2 - 4 } & $\begin{array}{l}\text { Supporting } \\
\text { Detail }\end{array}$ & $42 \%$ & $\begin{array}{l}\text { Provides details of } \\
\text { General Concept }\end{array}$ \\
\cline { 2 - 4 } & Standalone & $51 \%$ & $\begin{array}{l}\text { Not covered under a } \\
\text { General Concept or } \\
\text { Supporting Detail }\end{array}$ \\
\hline \multirow{3}{*}{$\begin{array}{l}\text { HSI } \\
\text { Technology }\end{array}$} & $\begin{array}{l}\text { Computer } \\
\text { Based }\end{array}$ & $48 \%$ & $\begin{array}{l}\text { Applies only to Computer } \\
\text { Based HSI }\end{array}$ \\
\cline { 2 - 4 } & $\begin{array}{l}\text { Non-Computer } \\
\text { Based }\end{array}$ & $20 \%$ & $\begin{array}{l}\text { Applies only to Non- } \\
\text { Computer Based HSI }\end{array}$ \\
\cline { 2 - 4 } & Both & $32 \%$ & $\begin{array}{l}\text { Applies to Computer and } \\
\text { Non-Computer Based HSI }\end{array}$ \\
\hline HSI Safety & Safety Basis & $45 \%$ & $\begin{array}{l}\text { Applies only to design of } \\
\text { HSI with a Safety Basis } \\
\text { function }\end{array}$ \\
& & $\begin{array}{l}\text { Applies to design of all } \\
\text { HSI }\end{array}$ \\
\cline { 2 - 4 } & $\begin{array}{l}\text { Non-Safety } \\
\text { Basis }\end{array}$ & $55 \%$ \\
\hline
\end{tabular}

General concept and associated supporting detail guidelines were identified when two or more guidelines addressed the same subject matter or topic. The general concept guideline represents the broadest or most general description of a common topic; for example, "Display formats should be consistent". Supporting detail guidelines represent specific instances or details associated with a common topic; for example, "Font style and size should be consistent between displays" and "Color coding should be consistent between displays". 110 general concept guidelines with over 600 associated supporting detail guidelines were identified through this process. A standalone guideline is any other guideline not identified as a general concept or supporting detail, or one that is sufficiently important or detailed to be considered individually. Approximately 740 standalone guidelines were identified.

Computer based guidelines include those that apply specifically to design features found in digital control systems; for example, "Cursors should have distinctive visual features." Non-computer guidelines refer to those design features not included in computer based control systems; for example, "Knobs for continuous adjustment controls should be round." 
PEC-SPS-2002-0015

Safety based guidelines refer to those that uniquely apply to control system safety functions; for example, "Critical safety function displays should be readable from the workstations of users needing access to these displays", as well as all supporting detail guidelines. Non-safety based guidelines include all remaining general concept and standalone guidelines. The assertion here is that general concept and standalone guidelines are sufficient in and of themselves for performing non-safety basis HFE analyses. However, supporting detail guidelines can always be considered at the discretion of the user and included in non-safety basis analyses.

When the classification process is applied to the evaluation of a specific HSI design, the result is a smaller more consistent starting set of guidelines from which to begin the evaluation, based on the HSI technology and safety function. For example, an evaluation using HFE-AT of a typical computer based control system with no safety functions would start with a set of 620 applicable guidelines, compared to 1648 guidelines using the DRG software tool.

\section{The Human Factors Engineering Analysis Tool (HFE-AT)}

WSRC has developed a software tool that helps to realize the gains in efficiency and consistency from automating the HFE evaluation process and applying the NUREG-0700 design guidelines in a graded approach. The software tool, entitled HFE-AT for Human Factors Engineering Analysis Tool, was designed to meet the following objectives:

- Capture NUREG-0700 guideline information, including the classifications determined by the WSRC analysis, in a relational database with the capability to search, filter, and query;

- Perform the basic HFE evaluation functions of the existing NRC software tool, DRG, and address its limitations;

- Automate the design guideline selection process using a structured, graded approach, based on the guideline classifications;

- Provide a PC compatible, intuitive user interface to facilitate in guideline selection, design evaluation, and management of the HFE evaluation process;

- Produce HFE evaluation reports in a form that are compatible with common desktop PC office applications;

- Provide a convenient means of adding guidelines to accommodate changes in HSI technologies, and to incorporate lessons learned resulting from industry and SRS experience; and

- Provide user assistance in the form of user help, a glossary, word search, and guideline filtering capabilities.

All of the NUREG-0700 guidelines, except those determined to have no added value, were loaded into a Microsoft Access database. The guidelines were organized in a hierarchy similar to that used in NUREG-0700 according to
Page 3 of 5

their design areas and sub areas. Fixed attributes associated with each guideline included: the design area and sub areas, the guideline title, a detailed guideline description, supplementary information about the guideline, a reference source, and the classifications resulting from the WSRC analysis. Dynamic attributes, entered through the HFE-AT user interface include: user access information; HFE evaluation identification, revision level, and scope; guideline selection and evaluation status; and supplemental information in the form of comments and attachments.

The user interface portion of the HFE-AT application was developed using Microsoft Visual Basic. The user begins the HFE evaluation process by creating a new analysis using the form in Figure 1. A number must be entered that uniquely identifies the evaluation, and a user ID is required to restrict access to the evaluation results. Optional information may be added to further describe the type and scope of the evaluation. The revision level is updated automatically by HFE-AT, and evaluation results for each revision are maintained by the application. Once the evaluation information is entered, the user must choose the initial method of guideline selection. If "Manual" is chosen, the user will manually select all of the guidelines to be used in the evaluation from the complete set of guidelines. By choosing "Computer Assisted" and specifying the system classification (Safety Basis vs. NonSafety Basis) and the system technology (Computer Based vs. Non-Computer Based) HFE-AT will select the starting set of guidelines based on the guideline analysis results discussed above.

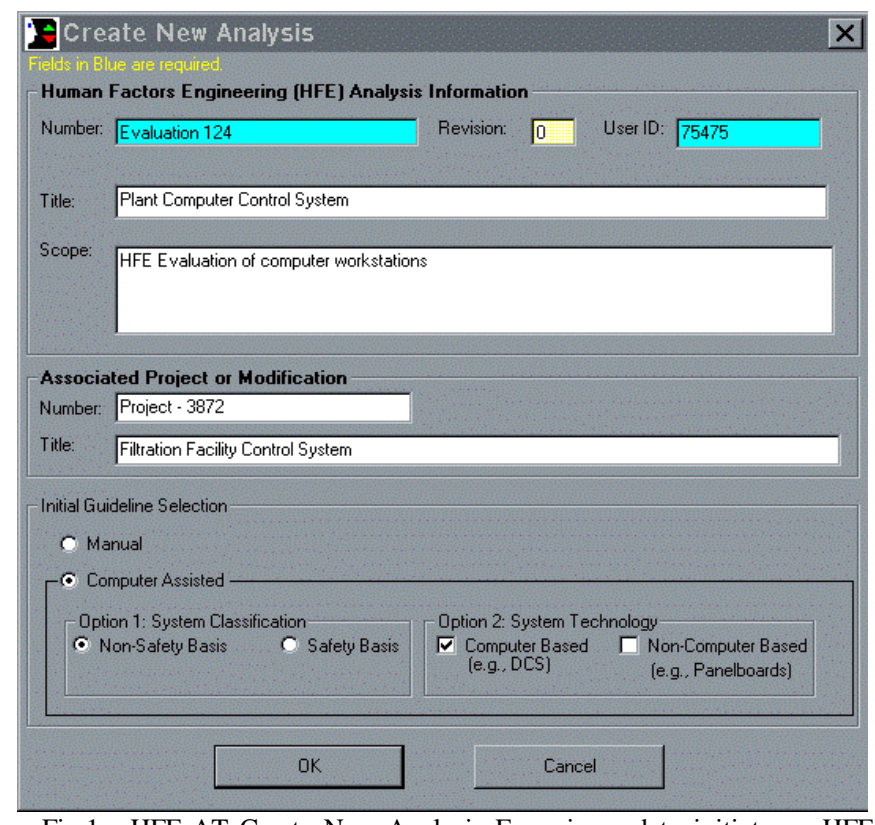

Fig.1. HFE-AT Create New Analysis Form is used to initiate an HFE Evaluation

Once the guideline selection method is chosen, the user can use the Guideline Selection Form in Figure 2 to add or delete guidelines from the set that will eventually be used in the HFE evaluation. 


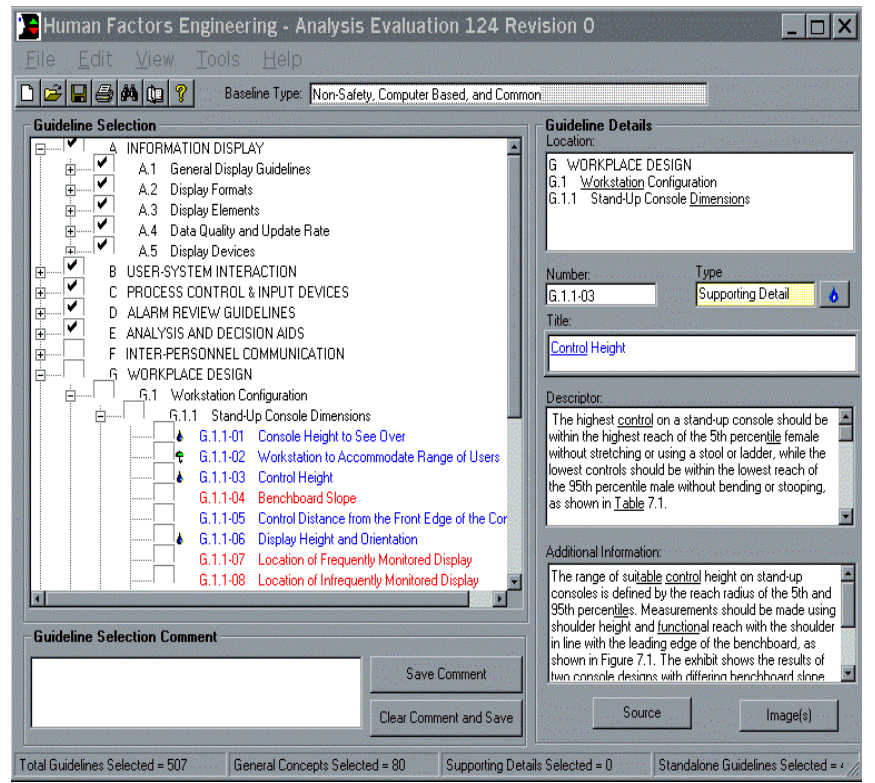

Fig. 2 HFE-AT Guideline Selection Form is used to select or delete individual guidelines from the HFE evaluation.

The Guideline Selection Form presents the starting set of guidelines in a ladder hierarchy that can be browsed similar to using Microsoft's Windows Explorer. Using a point and click approach, the user can drill down through the various sub levels, review individual guideline details, and select or deselect guidelines for the evaluation. A place for comments is provided to document the basis for deleting or selecting a specific guideline. The bottom of the form indicates the total number of guidelines selected and the distribution of guidelines by type (i.e., General Concept, Supporting Detail, or Standalone).

Once the final set of guidelines has been selected, the user will conduct the detailed design evaluation using the Guideline Analysis Form in Figure 3. The Guideline Analysis Form provides the capability to quickly navigate through the selected guidelines, individually or by section, and indicate the status of each guideline with respect to the HSI design analysis. Detailed guideline information is displayed for easy evaluation of individual guidelines. The user may select from six guideline statuses to indicate that:

- The guideline has not been evaluated,

- More information is needed,

- The design is non-compliant and further analysis is required before determining whether to "use as-is" or to "modify to comply",

- The guideline does not apply to the design,

- The design is non-compliant but should be used "as-is", or

- The design is compliant with the guideline.

These statuses make it possible to track the progress of the design evaluation and the basis for evaluation decisions. Comments and attachments can be added to support evaluation decisions. Filtering options allow the user to view subsets of
Page 4 of 5

the guidelines based on their type, status, keywords, comments, or attachments. User controls make it easy to go back and forth between forms, as necessary.

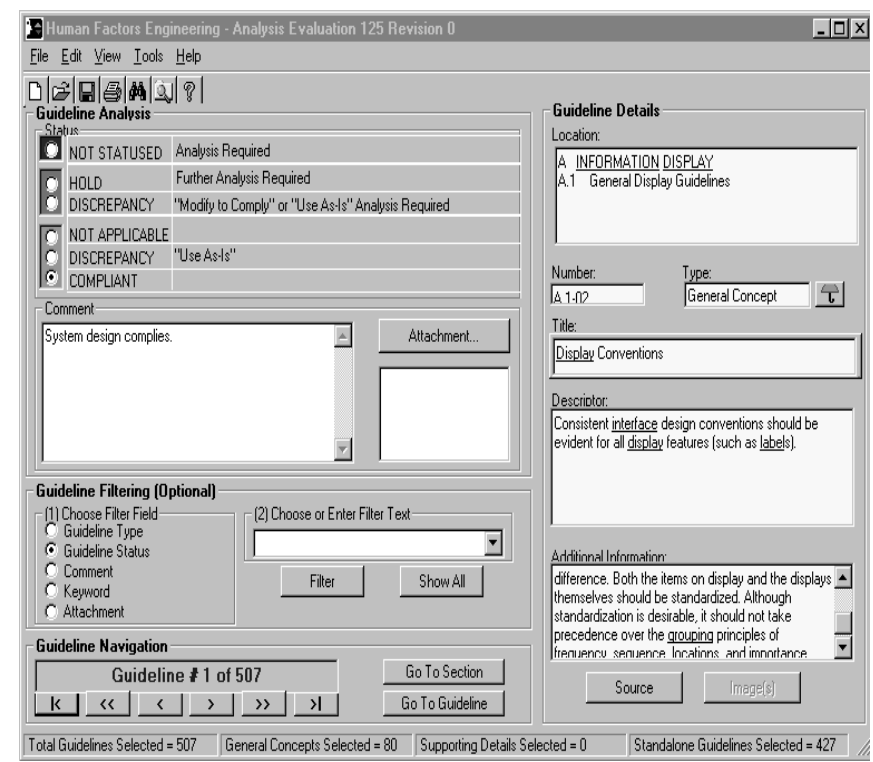

Fig. 3. HFE-AT Guideline Analysis Form is used to conduct a detailed HFE evaluation of the selected guidelines for a specific HSI design

At any time during the evaluation, the user may request a status report of the HFE evaluation. Figure 4 shows the Guideline Status Report Form that provides a numerical and statistical summary of the guideline selection and analysis.

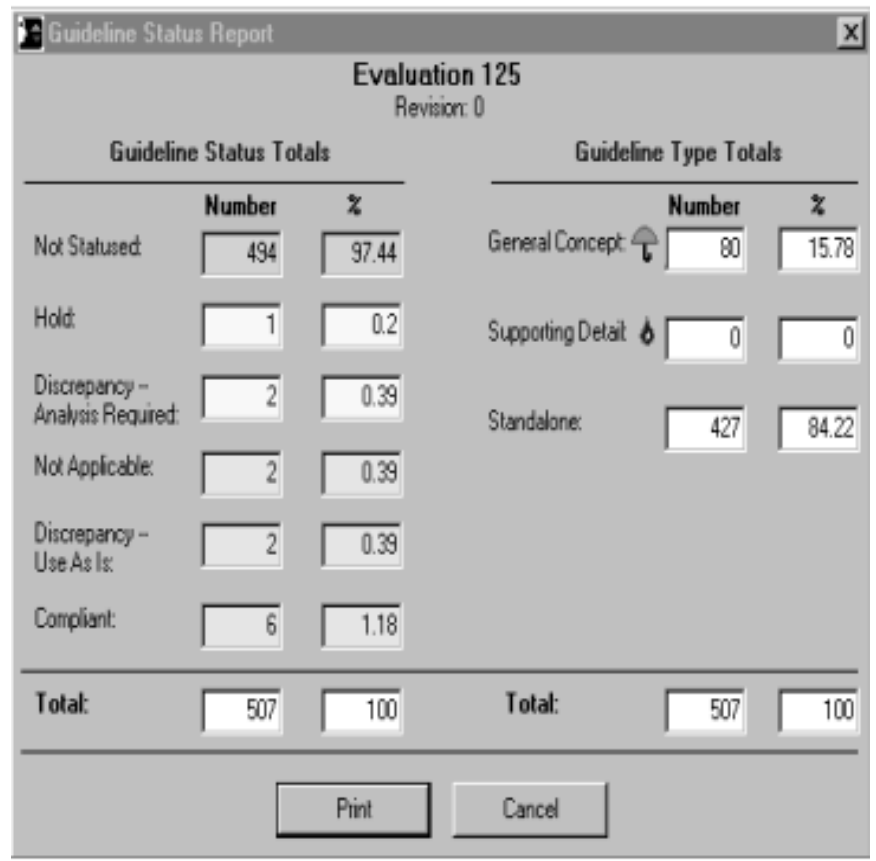

Fig. 4. HFE-AT Guideline Status Report Form provides current data on the status of an HFE evaluation of a specific HSI design

HFE-AT includes a variety of reporting options that enable the user to document the status or results of the HFE evaluation process by selecting different levels of detail and report content. The Print Options Form, shown in Figure 5, 
illustrates the types of reports and report content available. These reports may be printed or saved as a text file or as an HTML file for internet access.

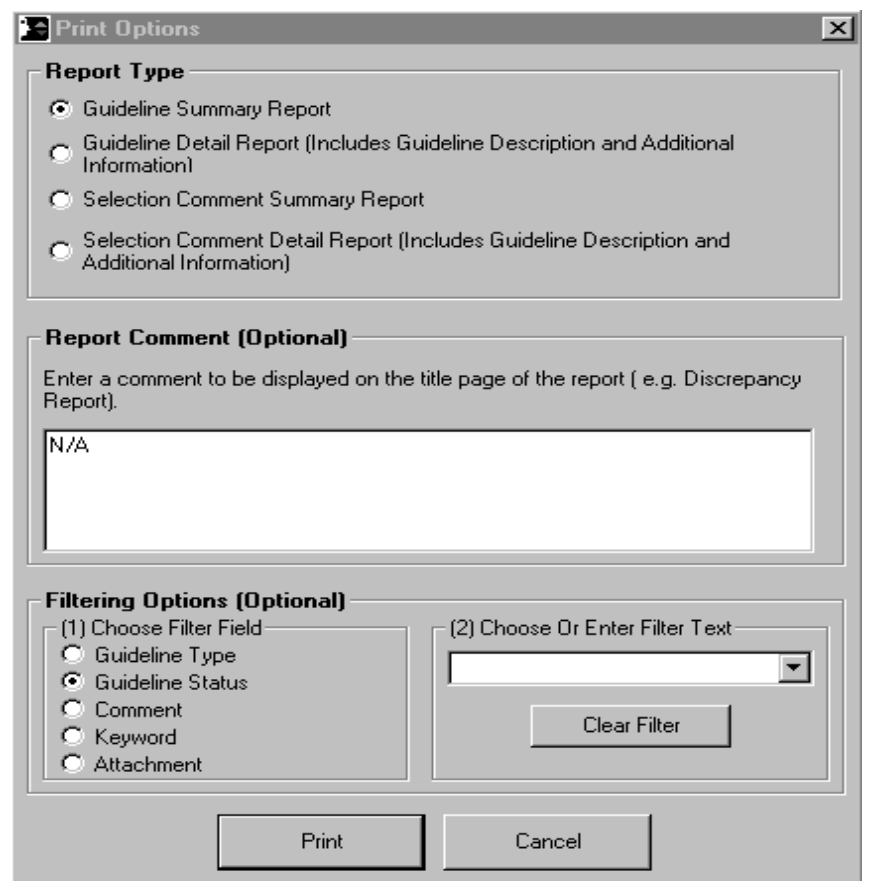

Fig. 5. HFE-AT Print Options Form provides a variety of choices for reporting HFE evaluation status and results

HFE-AT provides several features to help manage and control revisions to an HFE evaluation and to identify the difference between two revisions. It also includes a help utility and a complete glossary of terms and definitions.

\section{ACKNOWLEDGMENT}

The authors gratefully acknowledge the contributions of:

Beth Vail, Leroy Goff, Jr., and T. J. Voss of Westinghouse Safety Management Solutions and Laura Sheets of WSRC for conducting the NUREG-0700 guideline analysis;

Shawn Hull and Justin Weaver of WSRC for developing the HFE-AT application software; and

The SRS HFE Subcommittee for laying out the strategy for the automation of the HFE evaluation process.

\section{REFERENCES}

\section{Standards:}

[1] IEEE Guide for the Application of Human Factors Engineering to Systems, Equipment, and Facilities of Nuclear Power Generating Stations, IEEE Std 1023-1988, Dcember 12, 1988.

[2] IEEE Application Guide for Distributed Control and Monitoring for Power Plants, IEEE Std 1046-1991, October 25, 1991.

[3] IEEE Guide for the Application of Human Factors Engineering in the Design of Computer-Based Monitoring and control Displays for Nuclear Power Generating Stations, IEEE Std 1289-1998, May 27, 1998.

[4] IEEE Guide to Evaluation of Man-Machine Performance in Nuclear Power Generating Station Control Rooms and Other Peripheries, IEEE Std 845-1988, March 10, 1988.

[5] Human System Interface Design Review Guide, NUREG-0700, June 1996

\section{BIOGRAPHIES}

Page 5 of 5

Charles Mastromonico has a BS degree in Chemical Engineering from Rensselaer Polytechnic Institute, Troy, NY and an MS degree in Chemical Engineering from Clarkson University, Potsdam, NY.

His employment history includes: four years of research and development for the Air Force Rocket Propulsion Laboratory and twenty seven years of experience in the field of process automation and control with E. I. DuPont and the Westinghouse Savannah River Company, where he is currently employed as a Fellow Engineer.

Richard Izard has a BS degree in Chemical Engineering from Cornell University, Ithaca, NY.

His employment history includes: one year of research and development for the Eastman Kodak Company as a CO-OP student, and seventeen years of experience in the field of process automation and control with E. I. DuPont and the Westinghouse Savannah River Company, where he is currently employed as an Engineering Group Manager 